\title{
Myocarditis: A complication of COVID-19 and long-COVID-19 syndrome as a serious threat in modern cardiology
}

\author{
Lukasz Szarpak ${ }^{1,2,3}{ }^{\oplus}$, Michal Pruc ${ }^{3}$, Krzysztof J. Filipiak ${ }^{1}{ }^{1}$, Julia Popieluch ${ }^{4}$, \\ Andrzej Bielski ${ }^{3,5}$, Milosz J. Jaguszewski ${ }^{6}{ }^{\circ}$, Natasza Gilis-Malinowska ${ }^{6}$,

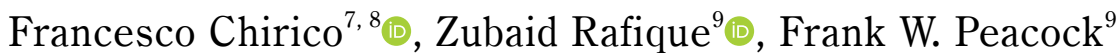 \\ ${ }^{1}$ Institute of Outcomes Research, Maria Sklodowska-Curie Medical Academy, Warsaw, Poland \\ ${ }^{2}$ Research Institute, Maria Sklodowska-Curie Bialystok Oncology Center, Bialystok, Poland \\ ${ }^{3}$ Research Unit, Polish Society of Disaster Medicine, Warsaw, Poland \\ ${ }^{4}$ Students Research Club, Maria Sklodowska-Curie Medical Academy, Warsaw, Poland \\ ${ }^{5}$ Polonia University, Czestochowa, Poland \\ ${ }^{6} 1^{\text {st }}$ Chair and Department of Cardiology, Medical University of Gdansk, Poland \\ ${ }^{7}$ Post-graduate School of Occupational Health, Università Cattolica del Sacro Cuore, Rome, Italy \\ ${ }^{8}$ Health Service Department, Italian State Police, Milan, Italy \\ ${ }^{9}$ Henry JN Taub Department of Emergency Medicine, Baylor College of Medicine, Houston, TX, United States
}

\section{This paper was guest edited by Prof. Togay Evrin}

Myocarditis is the inflammation of the heart muscle and is usually a consequence of a viral infection [1]. Because this disease can cause the destruction of myocytes, it may result in cardiomyopathy, heart failure, and sudden cardiac death. Cardiovascular complications from coronavirus disease 2019 (COVID-19) are emerging [2], especially during hospitalization, and myocarditis has been identified as a cause of death in some COVID-19 patients [3]. In the current epidemiological situation of a very large number of hospitalized patients, we must consider the long-term effects of myocarditis caused by the severe acute respiratory syndrome coronavirus 2 (SARS-CoV-2). Initial reports based on magnetic resonance imaging studies showed $78 \%$ of patients with myocardial abnormalities and $60 \%$ with ongoing myocarditis 2 to 3 months after COVID-19 infection. High blood troponin concentrations were also found in $76 \%$ of patients, although their heart function was preserved [4]. In other studies, about 10 weeks after SARS-CoV-2 infection, $37 \%$ of patients were also diagnosed with myocarditis, despite only half of the respondents having symptoms of COVID-19 infection [5]. In contrast, the most recent reports that analyzed data for a fifth of the United States (US) population showed that males between 12 and 17 years of age most likely developed myocarditis within 3 months of SARS-CoV-2 infection, with an incidence of approximately 450 per million infections. The most recent $\mathrm{CDC}$ reports, indicating the number of infected teenagers in the US is the highest in all age groups, suggest that myocarditis will become a significant burden [6]. The reports also estimate a 16 times higher risk in patients with COVID-19 compared to the general population, with an incidence of COVID-19-associated myocarditis of approximately 150 cases per 100,000 [7].

In light of these numbers, cardiac complications both during and after the SARS-CoV-2 infec-

Address for correspondence: Lukasz Szarpak, Assoc. Prof., PhD, DPH, MBA, DBA, LLM, Institute of Outcomes Research, Maria Sklodowska-Curie Medical Academy, ul. Solidarności 12, 03-411 Warszawa, Poland, e-mail: lukasz.szarpak@gmail.com 
tion will become a significant burden. Currently, the only effective method of preventing COVID-19 complications is vaccination, which reduces not only the risk of infection and mortality but also its long-term complications, i.e., long-COVID-19. In a study of 971,504 fully vaccinated people, only $0.2 \%$ developed COVID-19 symptoms, and only 31 developed long-COVID-19. On the other hand, the rate of COVID-19 infections was $11 \%$ in the unvaccinated group [8].

There is a lessor need to focus on myocarditis following mRNA vaccination [9]. This is because the infection and hospitalization rates are 17 times lower when compared to the unvaccinated group [10]. In summary, it is necessary to vaccinate the whole of society as soon as possible, perform further research on myocarditis in long-COVID-19 syndrome, create effective screening systems, and provide care for people suffering from long-COVID-19 syndrome before it leads to more serious complications.

\section{Acknowledgments}

The study was supported by the ERC Research Net and by the Polish Society of Disaster Medicine.

\section{Conflict of interest: None declared}

\section{References}

1. Pollack A, Kontorovich AR, Fuster V, et al. Viral myocarditis-diagnosis, treatment options, and current controversies. Nat Rev Cardiol. 2015; 12(11): 670-680, doi: 10.1038/nrcardio.2015.108, indexed in Pubmed: 26194549.

2. Robak O, Dudek M, Ladny JR, et al. Cardiac tamponade as a cause of COVID-19. Cardiol J. 2020; 27(6): 900-901, doi: 10.5603/CJ.2020.0175, indexed in Pubmed: 33432570.
3. Ruan Q, Yang K, Wang W, et al. Clinical predictors of mortality due to COVID-19 based on an analysis of data of 150 patients from Wuhan, China. Intensive Care Med. 2020; 46(6): 1294 -1297, doi: 10.1007/s00134-020-06028-z, indexed in Pubmed: 32253449.

4. Puntmann VO, Carerj ML, Wieters I, et al. Outcomes of cardiovascular magnetic resonance imaging in patients recently recovered from coronavirus disease 2019 (COVID-19). JAMA Cardiol. 2020; 5(11): 1265-1273, doi: 10.1001/jamacardio.2020.3557, indexed in Pubmed: 32730619.

5. Eiros R, Barreiro-Perez M, Martin-Garcia A, et al. Pericarditis and myocarditis long after SARS-CoV-2 infection: a cross-sectional descriptive study in health-care workers. medRxiv. 2020, doi: 10.1101/2020.07.12.20151316.

6. Singer ME, Taub IB, Kaelber DC. Risk of Myocarditis from COVID-19 Infection in People Under Age 20: A Population-Based Analysis. medRxiv. 2021, doi: 10.1101/2021.07.23.21260998, indexed in Pubmed: 34341797.

7. Boehmer TK, Kompaniyets L, Lavery AM, et al. Association Between COVID-19 and Myocarditis Using Hospital-Based Administrative Data - United States, March 2020-January 2021. MMWR Morb Mortal Wkly Rep. 2021; 70(35): 1228-1232, doi: 10.15585/mmwr.mm7035e5, indexed in Pubmed: 34473684.

8. Antonelli M, Penfold RS, Merino J, et al. Risk factors and disease profile of post-vaccination SARS-CoV-2 infection in UK users of the COVID Symptom Study app: a prospective, community-based, nested, case-control study. Lancet Infect Dis. 2021 [Epub ahead of print], doi: 10.1016/S1473-3099(21)00460-6, indexed in Pubmed: 34480857.

9. Diaz GA, Parsons GT, Gering SK, et al. Myocarditis and pericarditis after vaccination for COVID-19. JAMA. 2021; 326(12): 1210-1212, doi: 10.1001/jama.2021.13443, indexed in Pubmed: 34347001.

10. Delahoy MJ, Ujamaa D, Whitaker M, et al. Hospitalizations Associated with COVID-19 Among Children and Adolescents COVID-NET, 14 States, March 1, 2020-August 14, 2021. MMWR Morb Mortal Wkly Rep. 2021; 70(36): 1255-1260, doi: 10.15585/ mmwr.mm7036e2, indexed in Pubmed: 34499627. 
